\title{
Aqueous inorganic phase equilibria at high temperatures: some experimental, theoretical, and applied aspects
}

\author{
William L. Marsha11 \\ Chemistry Division, Oak Ridge National Laboratory, Oak Ridge, \\ Tennessee 37831 , USA
}

Abstract - Experimental studies generally performed at this laboratory on the solubility of particular salts and oxides in dilute and concentrated aqueous solutions of electrolytes at temperatures up to $400^{\circ} \mathrm{C}$ are presented. The techniques used are described. Some of this work applies an extended Debye-Hückel equation as a function of the ionic strength of the solution at the high temperatures. From the variation with temperature of a particular ionization or solubility equilibrium obtained from the studies, thermodynamic functions at infinite dilution of electrolyte are calculated. The studies describe solubility behavior of sulfate salts in exhibiting retrograde solubilities with increasing temperature. But some 2-2 sulfate salts, like magnesium or nickel sulfates, hydrolytically precipitate oxysulfates or hydroxides in nearly neutral solutions at about $200^{\circ} \mathrm{C}$. 0 ther sulfate, fluoride, and phosphate salts form two liquid phases at temperatures of $250-400^{\circ} \mathrm{C}$ at saturated vapor pressures. The solubility behavior of quartz and amorphous silica in salt solutions is reviewed. Some liquid-vapor critical phenomena are also presented. The studies are shown to apply to several fields such as water desalination, power plant steam generator chemistry, geochemistry, and chemical oceanography of deep ocean hot springs.

\section{INTRODUCTION}

Knowledge of phase equilibria of aqueous electrolytes at high temperatures and pressures is valuable for several fields of study. These fields include (a) geochemistry where hydrothermal processes are important, (b) chemical oceanography where in particular the solubilities of silica, silicates, carbonates, sulfates, and other substances are changed strongly by temperature, pressure, and the concentration of dissolved substances, (c) water desalination by distillation or reverse osmosis where the prevention of scale formation on heat exchanger surfaces is of crucial importance, (d) steam generator chemistry in power plants where problems of water impurity precipitations exist and can shut down a plant, and (e) all industrial processes that are concerned with the utilization of high temperature water containing dissolved substances that might precipitate, or where precipitation is a necessary part of the process.

Studies of the solubility of particular inorganic salts and oxides in water and in electrolyte-water solutions over wide ranges of temperature $\left(0-400^{\circ} \mathrm{C}\right)$ have been performed at this laboratory over the past 35 years as reviewed elsewhere (1-5). Included also are studies of inorganic liquid-liquid immiscibilities and of liquid-vapor critical temperatures. It is the purpose of this paper to review some of the experimental techniques that have been developed to make these studies and to present some of the interpretations by extended Debye-Hückel theory and other approaches.

A primary aspect is the application of the measurements and their interpretations for both fundamental and practical purposes. As one example, it is shown how the measurements are applied to the prevention of scale formation at high temperatures in water desalination 
processes or to the design of geothermal power plants in preventing silica deposition. The recent discoveries of sub-oceanic hydrothermal springs with vent temperatures up to $350^{\circ} \mathrm{C}$ have excited the interest of chemical oceanographers in understanding phase behavior of particular substances under these conditions. It should be emphasized that this paper reviews aqueous, high temperature solubility studies that have been performed essentially at this laboratory, including some studies that are believed to be unusual in several respects. Complex, hydrothermal geological systems are not discussed.

\section{EXPERIMENTAL METHODS}

Two general methods have been used for determining solubilities of a salt or other substances in water solution at temperatures above $100^{\circ} \mathrm{C}$, where the saturation vapor pressures exceed atmospheric pressure. These are the synthetic method, where a mixture of substances of total known composition is placed in a closed container and the temperature at which a second phase appears or disappears is determined, and the analytical method, where solid and liquid are equilibrated together and samples of the liquid phase are withdrawn for analysis.

\section{Synthetic Method}

The synthetic method can be very useful when the approach to equilibrium is rapid, and when a suitable method for detection of the phase transition is available. A detectable amount of the second phase must first form, and therefore the exact temperature for its initial formation may never be obtained. The closeness to the (exact) temperature of formation depends upon the nature of the system and the variables of the method of study. Supersaturation is also a problem and therefore, for solid-liquid equilibria, one may be limited to the determination only of the temperature of disappearance of a solid phase, and not of formation where supersaturation almost invariably occurs. Nevertheless, the synthetic method has been extremely useful in the research program at this laboratory in determining rather exact temperatures for the formation of two liquid phases at high temperatures and pressures and in determining liquid-vapor critical phenomena. For these two processes, supersaturation has not been observed in our studies of liquid-liquid immiscibility at temperatures of $250-400^{\circ} \mathrm{C}(6)$, and is non-existent in the determination of liquid-vapor critical phenomena $(6,7)$. With all studies of physical and chemical equilibria, one must be assured that equilibrium is closely approached or attained, and for the synthetic method, where the temperature is changed slowly with time, relatively good mixing of the system must be accomplished in order to (hopefully) maintain nearly equilibrium conditions as the temperature changes.

Since the liquid-vapor critical pressure of water is 221 bars at its critical temperature of $374^{\circ} \mathrm{C}$, and since it was desirable to use a visual method to detect phase transitions, we developed at this laboratory apparatus utilizing thick-wall glass capillary tubes for containing our systems under study. The capillary tubes, of either pyrex glass or fused silica with about $1 \mathrm{~mm}$ inside diameter and $3 \mathrm{~mm}$ outside diameter dimensions, ordinarily will withstand an internal pressure of 200-300 bars. The use of semi-micro techniques is advantageous in speed of observation (with a short-range telescope) and ease of preparation of samples for study. Detailed descriptions of two apparatus used are given in earlier publications $(8,9)$.

For determining visually the effect of hydrostatic pressure on liquid-phase formation, a small vessel with sapphire windows and platinum alloy gaskets was developed (10). This vessel was used at pressures up to 1800 bars and temperatures to $450^{\circ} \mathrm{C}$. Hydrostatic pressure was generated by means of a diaphragm pressure pump; a small short-range telescope was used to detect two-liquid-phase appearances or disappearances as the pressure was varied. Another apparatus employing a glass to metal tube seal was used for making similar studies of the effect of pressure on liquid-liquid immiscibility, but at pressures not greater than 300 bars (11).

Analytical Method

The analytical method can be used for reactions that approach equilibrium at either fast or slow rates. Thus, before the solution phase is sampled, the mixture of the two phases 
may have been equilibrated for a few minutes to hours and even to months for very slow solubilization or reaction rates (for example, for geologic analogue systems). Problems may and do arise, however, in obtaining an inert container for the studies. Also, the identification of the saturating solid phase or phases must be established either by prior knowledge or by rapidly cooling the containment vessel and removal of solid for analysis.

The analytical method is conventionally used for solubility determinations at low temperatures and atmospheric pressure, and is the method that we have used extensively in our studies of solid-liquid equilibria at high temperatures and high pressures. It was necessary to develop small high pressure vessels to contain the mixtures of solid and liquid to be equilibrated, and in this respect we devised both the vessels and a furnacethermostat assembly to hold eight vessels simultaneously. These eight vessels containing different compositions of a saturating solid phase (or phases) and solution phase are rocked at a constant temperature in the apparatus. The solution phases are sampled periodically, through connecting metal capillary tubes and valves, and analyzed at the laboratory bench. A porous tefion disc was incorporated directly into each pressure vessel for filtering the solution during the sampling process. Teflon was found to be suitable for this use at temperatures up to $350^{\circ} \mathrm{C}$ over relatively short periods of time (12). Teflon was also used as a gasketing material, although metal, split rings were necessary for use above $325^{\circ} \mathrm{C}$ to contain the teflon, which undergoes a phase transition near this temperature. Detailed descriptions of the apparatus and experimental procedures are given in earlier publications $(13,14)$.

In another analytical method, where it was necessary to determine the compositions of two liquid phases in equilibrium at high temperatures and pressures, large bore ( 8-10 mm inside diameter) fused silica or pyrex glass tubes were used for containing the solution mixtures. Ten to twelve of these sealed tubes, containing solutions, were placed in a large, commercially available, high pressure vessel, which contained a small amount of liquid water to counter-balance the high pressure (that develops at high temperature) within each of the sealed glass tubes. The large vessel was then equilibrated at a high, constant temperature where liquid-liquid immiscibility was known to occur for the particular compositions (by using the synthetic method). After equilibrium was attained, the vessel was removed from the furnace and rapidly cooled in an ice-water or dry-ice trichloroethylene mixture while always being kept in a vertical position to prevent mixing (and redissolution) of the two liquid phases. [At temperatures near $25^{\circ} \mathrm{C}$, the concentrated liquid phases of the systems studied generally converted to gels.] The vessel was opened and each glass tube was cut at the proper positions in order to remove a segment of both phases for chemical analysis. Details of this procedure and typical analytical results obtained are given elsewhere (15).

\section{SPECIFIC STUDIES}

Solubility of Calcium Sulfate in Electrolyte-Water Systems

Calcium sulfate and its two hydrates were chosen at an earlier time as appropriate salts to be used for solubility studies in electrolyte solutions at high temperatures for several reasons. First, calcium sulfate is present in significant concentrations in seawater and in many brackish waters, but shows decreasing solubility with rising temperature. Thus, precipitation of calcium sulfate may occur if seawater is heated to temperatures above about $113^{\circ} \mathrm{C}$. Knowledge of this behavior is important in designing a water desalination plant to prevent scale formation. Second, the solubility is sufficiently low that the salt and its hydrates could be used to test the applicability of extended Debye-Hückel theory both at low and high temperatures. Third, these low solubilities allow the use of calcium sulfate in determining the ionization (or association) behavior of other electrolytes and also of calcium sulfate as discussed later in this paper.

An extended Debye-Hackel expression for the solubility of a 2-2 salt can be written as follows (16):

$$
\begin{gathered}
\log Q_{s p}=\log K_{s p}+8 S \sqrt{I} /\left(1+A_{s p} \sqrt{I}\right) \\
+B^{-} I+C^{-} I^{2}
\end{gathered}
$$


where Qsp is the solubility product of a salt at ionic strength $I$, $K_{s p}$ is the (thermodynamic) solubility product at zero ionic strength, 85 is the theoretical Debye-Hückel limiting slope for a 2-2 salt, $A_{S p}$ is the adjustable "ion size" parameter and $B^{\prime}$ and $C^{\prime}$ are adjustable empirical parameters. This relationship was found to fit the solubility of calcium sulfate and its two hydrates [CaSO $4 \cdot 2 \mathrm{H}_{2} \mathrm{O}$ (gypsum) and $\mathrm{CaSO}_{4} \cdot 1 / 2 \mathrm{H}_{2} \mathrm{O}$ (hemihydrate)] in several uncommon-ion electrolyte media at ionic strengths as high as 6 molal and at temperatures from 0 to $350^{\circ} \mathrm{C}$. These studies followed the earlier numerous solubility studies, performed at this laboratory, of Lietzke and Stoughton on silver sulfate in aqueous electrolyte media at temperatures up to $250^{\circ} \mathrm{C}$ in which they successfully applied Debye-Hückel theory (17). An example of the solubility of calcium sulfate in $\mathrm{NaNO}_{3}-\mathrm{H}_{2} \mathrm{O}$ electrolyte solutions at temperatures from 125 to $350^{\circ} \mathrm{C}$ and at ionic strengths to 6 molal is shown in Fig. 1 (18). These solubilities adhere to the extended Debye-Hückel equation up to moderate ionic strengths. Similar behavior has been observed for the solubility of calcium sulfate in aqueous sodium chloride $(16,19)$ and sodium perchlorate (20), and also for the base, calcium hydroxide, in sodium nitrate solutions to $350^{\circ} \mathrm{C}(21)$. The activity coefficients $\left(\gamma_{ \pm}\right)$for a salt such as $\mathrm{CaSO}_{4}$ can be described by the following equation (19):

$$
r_{ \pm\left(\mathrm{CaSO}_{4}\right)}=\sqrt{\frac{K_{s p}}{Q_{s p}}}
$$

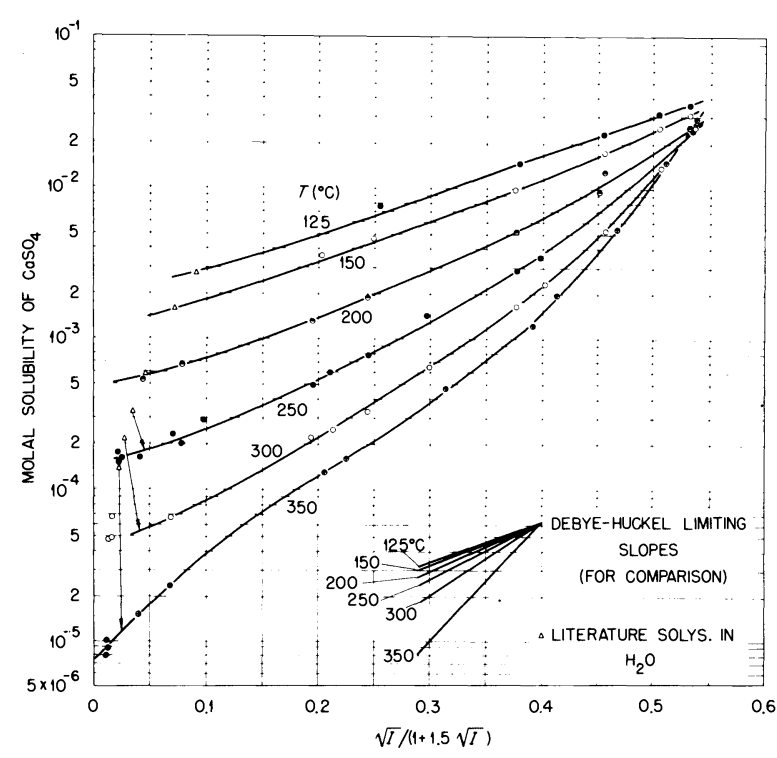

Fig. 1. The solubility of $\mathrm{CaSO}_{4}$ in $\mathrm{NaNO}_{3}-\mathrm{H}_{2} \mathrm{O}$ solutions, $125-350^{\circ} \mathrm{C}$, vs. a function of the ionic strength, I.

A plot of $\log \gamma_{ \pm}\left(\mathrm{CaSO}_{4}\right)$ vs. $\sqrt{\mathrm{I} /}\left(1+\mathrm{A}_{\mathrm{sp}} \sqrt{\mathrm{I}}\right)$ in Fig. 2 shows how these values for the solubility of $\mathrm{CaSO}_{4}$ in aqueous $\mathrm{NaCl}$ solutions, normalized to a limiting Debye-Hückel slope at $25^{\circ} \mathrm{C}(19)$, provide a relatively simple description to moderately high ionic strengths and further confirm the applicability of extended Debye-Hückel theory at high temperatures.

Sodium Sulfate Solubilities in Electrolye Solutions

With the success attained in applying Debye-Hückel theory for solubilities of 2-2 electrolytes, solubilities were obtained for a 1-2 salt, sodium sulfate, separately in aqueous sodium chloride and sulfuric acid, and in aqueous mixtures of the two electrolytes at temperatures up to $350^{\circ} \mathrm{C}(22)$. These experimental solubilities for sodium sulfate were described by application of the extended Debye-Hückel equation and the second ionization constant for $\mathrm{HSO}_{4}^{-}$, the ion product of $\mathrm{H}_{2} \mathrm{O}$, and the variation of their quotients with ionic strength obtained from earlier studies at this laboratory $(12,23,24)$. A combination of these separate values together with the experimental solubilities allowed the description of behavior as shown in Fig. 3, where the straight lines represent the theoretical Debye-Hückel slopes. Thus, at a given temperature $\left(275\right.$ to $\left.350^{\circ} \mathrm{C}\right)$, the logarithm of the 


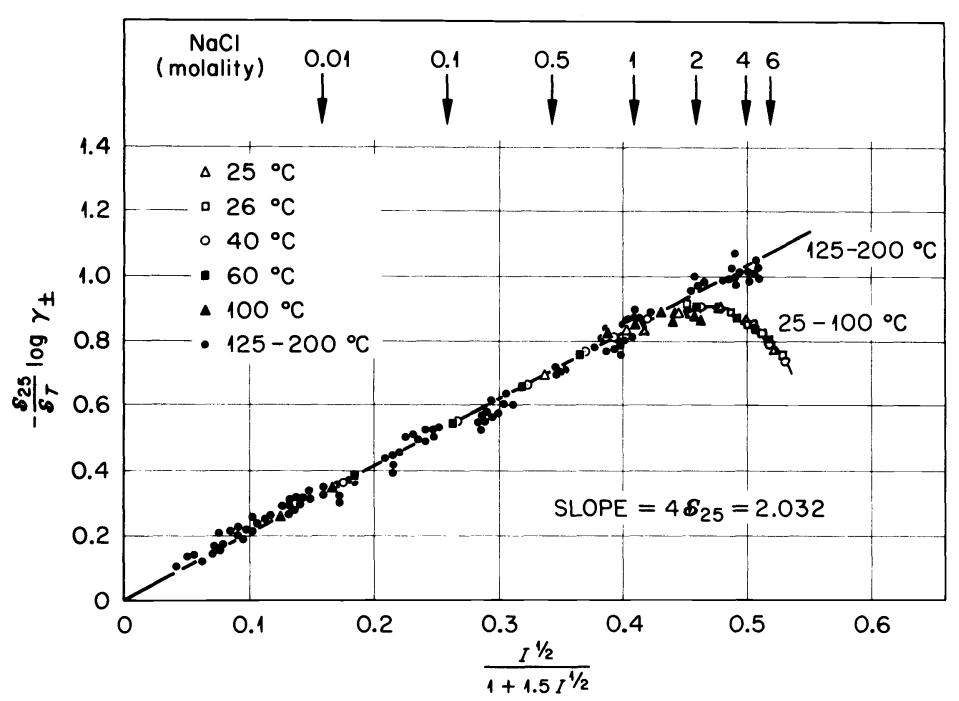

Fig. 2. Variation of $-\log \gamma_{+}$with $I^{1 / 2} /\left(1+1.5 I^{1 / 2}\right)$ for the solubility of $\mathrm{CaSO}_{4}$ and its hydrates in $\mathrm{NaCl}-\mathrm{H}_{2} \mathrm{O}, 25-200^{\circ} \mathrm{C}$; Debye-Huckel slopes, ST, normalized to value at $25^{\circ} \mathrm{C}$.

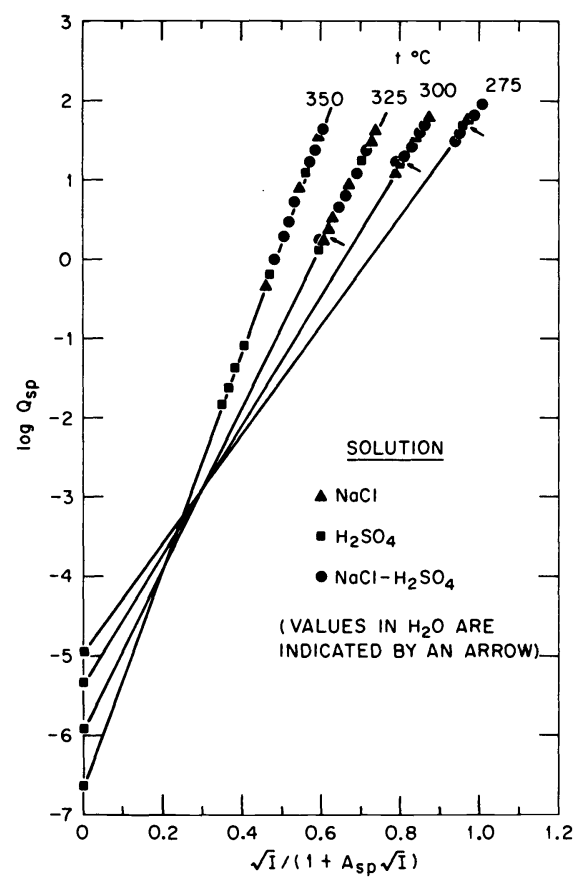

Fig. 3. Plots of the logarithm of the solubility quotient (Qsp) of $\mathrm{Na}_{2} \mathrm{SO}_{4}$ in aqueous solutions of $\mathrm{H}_{2} \mathrm{SO}_{4}, \mathrm{NaCl}$, and in $\mathrm{H}_{2} \mathrm{SO}_{4}-\mathrm{NaCl}$ solutions vs $\sqrt{\mathrm{I}} /\left(1+\mathrm{A}_{\mathrm{sp}} \sqrt{\mathrm{I}}\right)$ at $275-350^{\circ} \mathrm{C}$. The straight lines represent Debye-Hückel theoretical slopes.

solubility product of $\mathrm{Na}_{2} \mathrm{SO}_{4}$ in mixed solutions of $\mathrm{NaCl}$ and $\mathrm{H}_{2} \mathrm{SO}_{4}$ is described by a single straight line that adheres to the Debye-Hückel limiting slope to high concentrations of electrolyte. This behavior allows the prediction of solubilities of this naturally abundant salt, $\mathrm{Na}_{2} \mathrm{SO}_{4}$, for application to several fields to be discussed later. 
Solubility Behavior of 3-2 Electrolytes

To test the use of Debye-Hückel theory for application to a 3-2 electrolyte salt, the solubilities of lanthanum sulfate $\left[\mathrm{La}_{2}\left(\mathrm{SO}_{4}\right)_{3}\right]$ and of samarium sulfate $\left[\mathrm{Sm}_{2}\left(\mathrm{SO}_{4}\right)_{3}\right]$ were studied in water and sulfuric acid solutions at temperatures up to 160 and $250^{\circ} \mathrm{C}$, respectively $(25,26)$. Both salts adhered well to a Debye-Hückel limiting slope, and therefore confirmed the generality of the extended theory for application with the multivalent salts. Figure 4 shows the adherence of $\log Q_{s p}$ for samarium sulfate to the Debye-Hückel function at 150 to $250^{\circ} \mathrm{C}$.

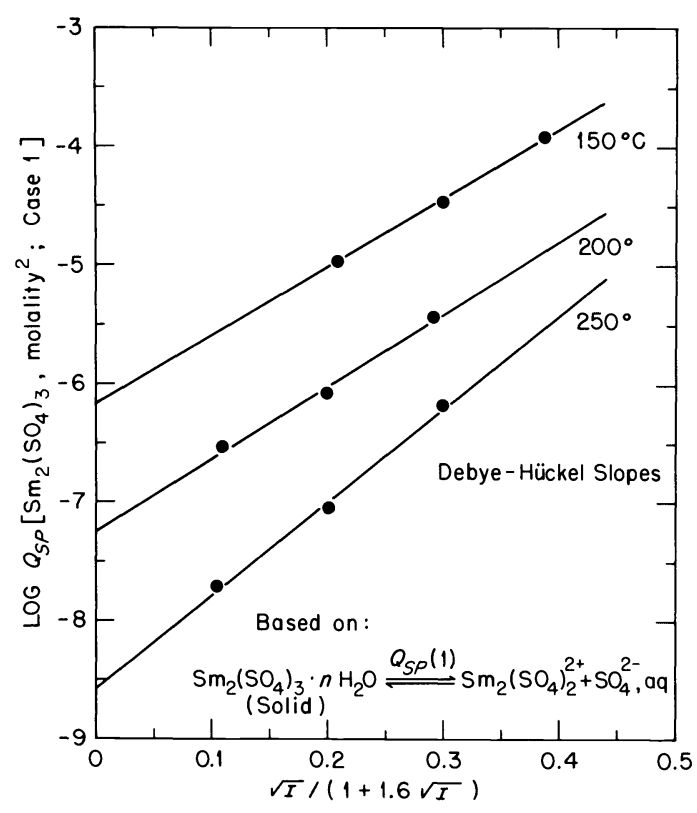

Fig. 4. Log solubility products $\left[\mathrm{Qsp}_{\mathrm{sp}}(1)\right]$ for $\mathrm{Sm}_{2}\left(\mathrm{SO}_{4}\right)_{3}$ hydrate vs a function of ionic strength (I), $150-250^{\circ} \mathrm{C}$.

Ionization Equilibria from Solubility of Sulfates in Sulfuric and Nitric Acids and in Multiple Electrolyte Systems

The earlier, observed adherence of solubilities to an extended Debye-Hückel equation at high temperatures $(17,19)$ allows the use of solubility as a method to determine ionization (or association) equilibrium constants. Lietzke, Stoughton, and Young employed $\mathrm{Ag}_{2} \mathrm{SO}_{4}$ as a saturating solid in determining the second ionization constant of aqueous sulfuric acid to $225^{\circ} \mathrm{C}(17 \mathrm{~b})$. Similarly, a second ionization quotient (a mass action expression utilizing concentration at a given ionic strength) of sulfuric acid can be obtained from the observed increase in solubility of $\mathrm{CaSO}_{4}$ in a sulfuric acid solution over that in a solution containing only a 1-1 electrolyte salt, such as $\mathrm{NaCl}$, of the same ionic strength. This increase is attributed to the formation of the bisulfate ion, $\mathrm{HSO}_{4}^{-}$(12). From solubilities at constant temperature over a wide range of ionic strength, many second ionization quotients $\left(Q_{2}\right)$ were calculated. By extrapolating these values to zero ionic strength with the use of extended Debye-Hückel theory, an ionization constant ( $\left.K_{2}\right)$ is obtained. From the value of $K_{2}$ and the many values of $Q_{2}$, products of activity coefficients $\left[\mathrm{r}\left(\mathrm{HSO}_{4}^{-}\right)\right]$, as defined on $\mathrm{Fig}$. 5, were calculated for the particular temperature and, with additional experiments, for other temperatures from 25 to $350^{\circ} \mathrm{C}$. By normalization of $\log \left[\mathrm{r}\left(\mathrm{HSO}_{4}^{-}\right]\right.$to the Debye-Hückel limiting slope at $25^{\circ} \mathrm{C}$, all values of $10 \mathrm{~g}$ $\left[\mathrm{r}\left(\mathrm{HSO}_{4}{ }^{-}\right)\right]$fall essentially on one line as shown in Fig. 5 (12). Again, relative simplicity is observed in describing the product of these activity coefficients for the second ionization constants of $\mathrm{H}_{2} \mathrm{SO}_{4}$ from 25 to $350^{\circ} \mathrm{C}$.

Similar approaches have been taken for studies of $\mathrm{CaSO}_{4}$ and its hydrates in synthetic seawater and in seawater concentrates (termed seasalt solutions) from which the ionization quotients and constants of magnesium sulfate were determined from 0 to $200^{\circ} \mathrm{C}(27,28)$. 


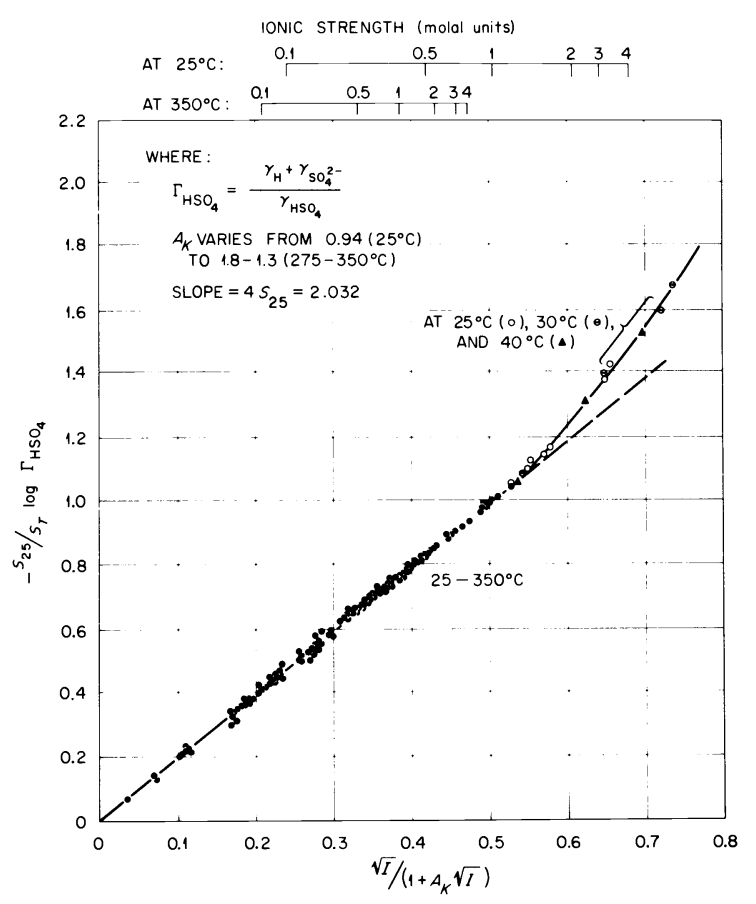

Fig. 5. Variation of $\log \mathrm{rHSO}_{4}-$ (product of activity coefficients for dissociation of $\mathrm{HSO}_{4}^{-}$) with a function of the ionic strength (I) from 25 to $350^{\circ} \mathrm{C}$; slopes normalized to Debye-Hückel slope at $25^{\circ} \mathrm{C}$

Solubilities of $\mathrm{CaSO}_{4}$ in nitric acid solutions at $100-350^{\circ} \mathrm{C}$ have yielded ionization constants of nitric acid by a similar method (29). These same ionization constants have been obtained at $300-370^{\circ} \mathrm{C}$ from solubilities of $\mathrm{MgSO}_{4}$ in aqueous nitric acid (30).

\section{Ionization Behavior of Saturating Salt}

The ionization behavior of the saturating salt can also be determined from its solubility in a multiple aqueous salt system such as $\mathrm{NaNO}_{3}-\mathrm{Na}_{2} \mathrm{SO}_{4}-\mathrm{H}_{2} \mathrm{O}$ (31). In this type of study the solubility of the salt (in this example, $\mathrm{CaSO}_{4}$ ) was determined in a series of mixtures of $\mathrm{NaNO}_{3}$ and $\mathrm{Na}_{2} \mathrm{SO}_{4}$ or of $\mathrm{NaClO}_{4}$ and $\mathrm{Na}_{2} \mathrm{SO}_{4}$ (32) while the formal ionic strength of the various mixtures was kept the same. It is assumed that under this condition of constant ionic strength the activity coefficients will remain constant. The following equilibria are taken to apply,

$$
\begin{aligned}
& \mathrm{CaSO}_{4} \text { (solid) } \stackrel{\mathrm{Qu}}{*} \mathrm{CaSO}_{4}^{\circ} \text { (solution) } \\
& \mathrm{CaSO}_{4}^{\circ} \text { (solution) } \stackrel{\mathrm{Qd}}{*} \mathrm{Ca}^{2+}+\mathrm{SO}_{4}{ }^{2-}
\end{aligned}
$$

whereby,

$$
\begin{aligned}
s & =\left[\mathrm{CaSO}_{4}{ }^{0}\right]+\left[\mathrm{Ca}^{2+}\right] \\
& =Q_{u}+\frac{Q_{i s p}}{\left[\mathrm{SO}_{4}(\text { total })-Q_{u}\right]}
\end{aligned}
$$

where $s$ is the molal solubility, $Q_{u}, Q_{d}$, and $Q_{i} s p$ are the solubility "quotient" of neutral $\mathrm{CaSO}_{4}$, the ionization "quotient", and the ionic solubility product "quotient", respectively, and where $Q_{i s p}$ equals $Q_{u} \cdot Q_{d}$ at the constant ionic strength for the series of experiments. The solubility of $\mathrm{CaSO}_{4}$ (or its hydrates) has adhered to the straight line 
form of equation 6 at temperatures from 0 to $350^{\circ} \mathrm{C}$ and at several constant ionic strengths from 0.24 to 5.8 molal $(31,32)$. An example of this straight line behavior at $250^{\circ} \mathrm{C}$ is shown in Fig. 6, where $1 /\left[\mathrm{SO}_{4}^{2-}\right]$ equals $1 /\left[\mathrm{SO}_{4}\right.$ (total) - $\left.\mathrm{Qu}\right]$. This observation lends considerable support for the assumptions made and allows the determination of the ionic solubility product constant $\left(\mathrm{K}_{j} \mathrm{sp}\right)$ of $\mathrm{CaSO}_{4}$ over the above range of temperature.

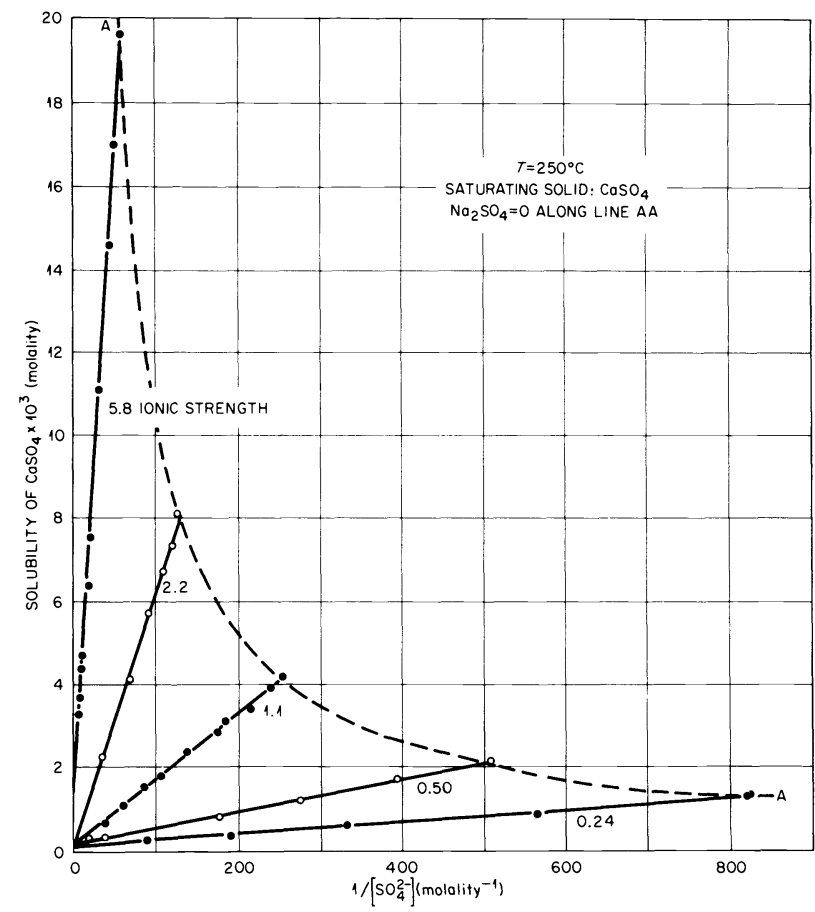

Fig. 6. Solubility of $\mathrm{CaSO}_{4}$ in $\mathrm{Na}_{2} \mathrm{SO}_{4}-\mathrm{NaNO}_{3}-\mathrm{H}_{2} \mathrm{O}$ solutions at $250^{\circ} \mathrm{C}$ and several constant ionic strengths (See equation 6 ).

Amorphous Silica and Quartz Solubilities in Salt Solutions

The solubilities of amorphous silica in several separate and mixed salt solutions and of quartz in water and sodium chloride solutions have been presented in recent papers $(33-41)$. These studies have shown that the solubility of quartz or of amorphous silica is directly proportional to the concentration of "free" or "effective" water $(34,39,41)$. This "effective" concentration of water is obtained with use of the solution densities by subtraction of the amount of water believed to solvate the solute species $(39,41)$. This procedure provides one predictive approach to the solubility behavior of amorphous silica and quartz that appears to have a chemical significance for the equilibria involved.

In another predictive approach, these solubility studies have revealed a simple straight line relationship at a given temperature of the logarithm of amorphous silica solubility (expressed as molarity) versus the molarity of added salt (35). Examples at $25^{\circ} \mathrm{C}$ are shown in Fig. 7 for this solubility behavior in several different, added salt solutions (35). In Fig. 7 all solubilities have been normalized to the value in pure water, where $\gamma\left(\mathrm{SiO}_{2}\right)$, the molar activity coefficient, equals $\mathrm{S}^{\circ}$ (in $\left.\mathrm{H}_{2} \mathrm{O}\right) / \mathrm{S}$ (in salt solution) and $\mathrm{S}$ is the molar solubility. This same behavior is observed for solubilities of amorphous silica solutions in separate salt solutions up to $350^{\circ} \mathrm{C}$ although, because of the greater experimental difficulties and lack of accurate density data for some of the salts, there is a greater scatter of data than at $25^{\circ} \mathrm{C}$. Plots of experimentally determined molal solubilities of amorphous silica in aqueous $\mathrm{NaCl}, \mathrm{NaNO}_{3}, \mathrm{MgCl}_{2}, \mathrm{Na}_{2} \mathrm{SO}_{4}$, and $\mathrm{MgSO}_{4}$ solutions versus molality of added salt at 25 to $350^{\circ} \mathrm{C}$ are given in Fig. 8 (36). The increase, rather than decrease, in solubility in $\mathrm{Na}_{2} \mathrm{SO}_{4}$ solutions at high temperatures is explained by the formation of a $\mathrm{Si}(\mathrm{OH})_{2} \cdot \mathrm{SO}_{4}{ }^{2-}$ complex (38). Hydrolytic precipitation of magnesium oxysulfates and $\mathrm{Mg}(\mathrm{OH})_{2}$ at $200^{\circ} \mathrm{C}$ and above does not allow the attainment of high concentrations of $\mathrm{MgSO}_{4}$ above that temperature. The additive solubility behavior of amorphous silica was applied for reasonable calculations of its solubility in mixed aqueous electrolytes at 25 


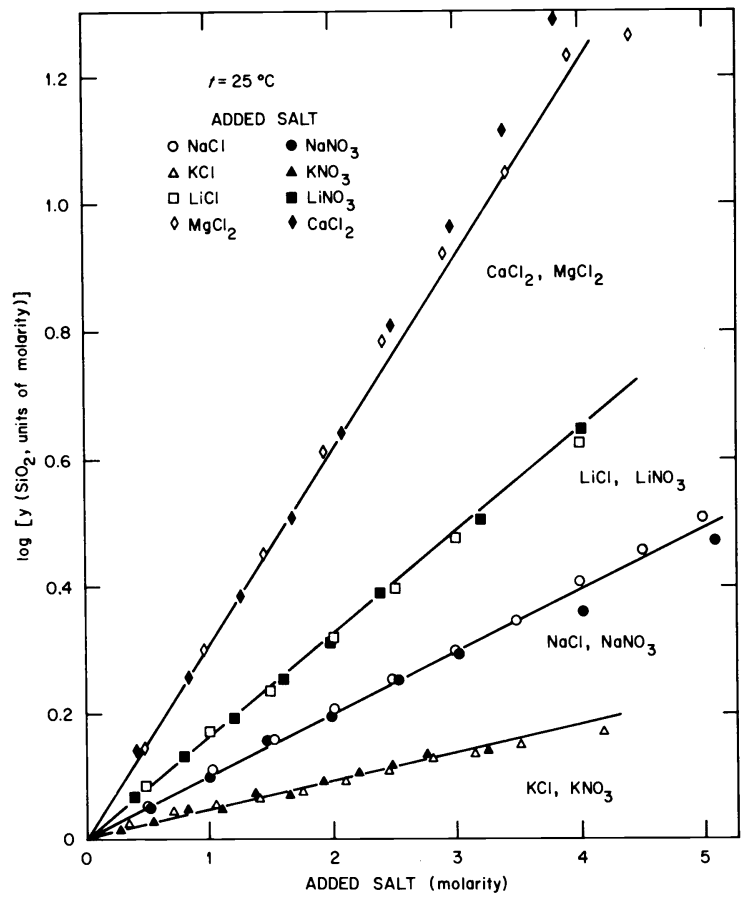

Fig. 7. Logarithm of molar activity coefficients of amorphous silica vs, molarity of added salt for different salt solutions at $25^{\circ} \mathrm{C}$.

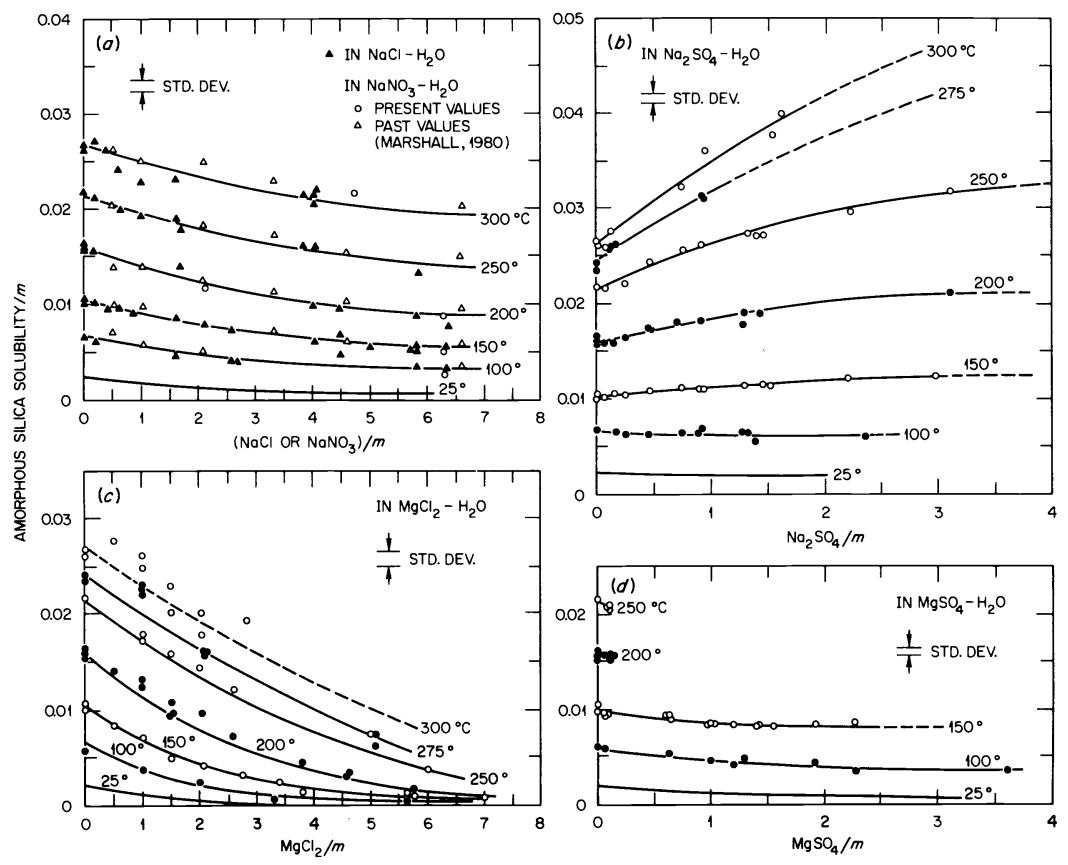

Fig. 8. The molal solubility of amorphous silica in aqueous $\mathrm{NaCl}, \mathrm{Na}_{2} \mathrm{SO}_{4}, \mathrm{MgCl}_{2}$, and $\mathrm{MgSO}_{4}$ solutions, $25-300^{\circ} \mathrm{C}$.

to $350^{\circ} \mathrm{C}(37)$. Thus, the solubility of amorphous silica is now predictable in natural solutions at high temperatures, for example, in hydrothermal seawater, geothermal brines, brackish waters, or in concentrates in steam generators. 
Thermodynamic Functions from Solubility

When a solubility product constant or ionization constant is known as a function of temperature, the standard change in enthalpy $(\Delta H)$ for the reaction process can be obtained at a particular temperature from the use of the van't Hoff isochore, whereby in $K$ is plotted against $1 / T(K)$. The slope is equal to $-\Delta H / R$ where $R$ is the gas constant. Since the standard change in Gibbs free energy $(\Delta G)$ is equal to $-R T$ In $K$, the change in entropy $(\Delta S)$ is obtained from the relation, $\Delta G=\Delta H-T \Delta S$. If the variation in In $K$ with pressure is known, a standard volume change $(\Delta V)$ may be calculated, and consequently the change in internal energy $(\Delta E)$ may be obtained by the thermodynamic relationships,

$$
\begin{gathered}
\left(\frac{\partial \ln K}{\partial P}\right)_{T}=\frac{-\Delta V}{R T} \\
\Delta E=\Delta H-P \Delta V
\end{gathered}
$$

The quantity, $\Delta V$, may also be obtained by knowing the average net change in number of moles of solvent participating in a solubility or ionization reaction and by applying the concept of a complete equilibrium constant (42) as discussed later.

Solubility measurements therefore allow the determination of thermodynamic functions not only for the equilibrium involving the saturating substance but also for other aqueous, homogeneous electrolyte equilibria where the ionization constants are determined indirectly from solubility measurements. Tabulations of some thermodynamic functions from solubility studies at high temperatures at this laboratory are given in several published papers $(15-17,19,21,28,31,43)$. Figure 9 shows plots of $\log K_{s p}$ versus $1 / T(K)$ for several saturated sulfate salts from which their thermodynamic functions may be obtained (43).

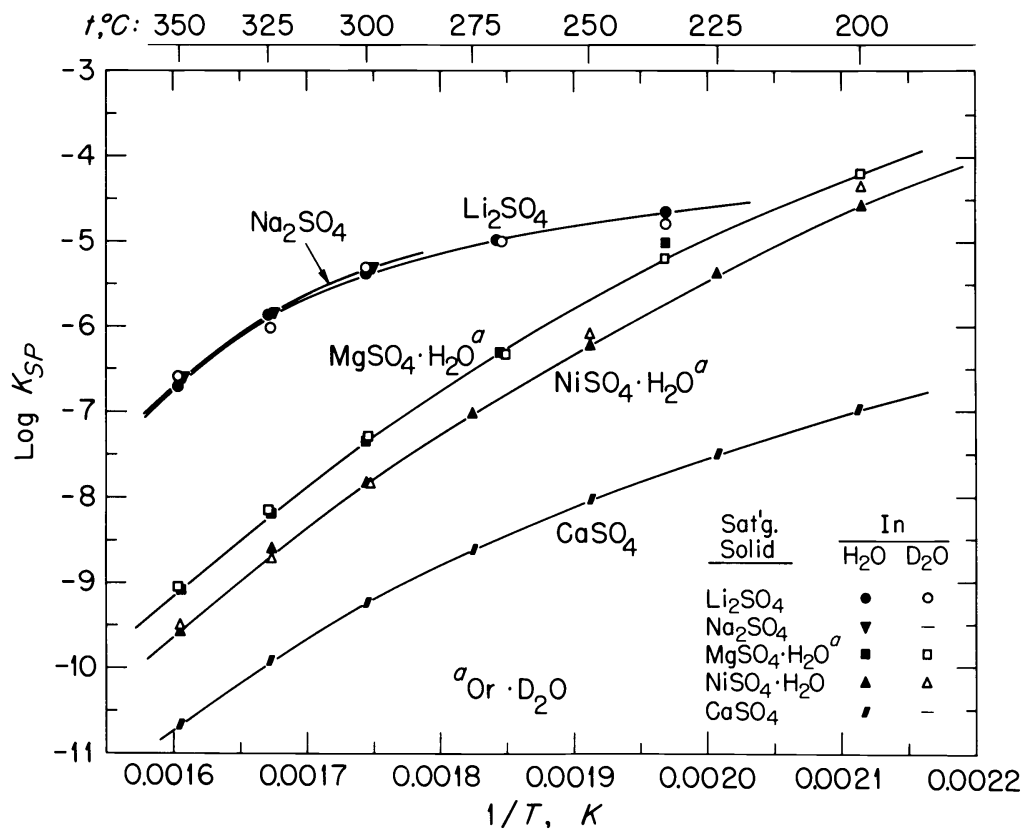

Fig. 9. Log solubility product constants ( $\left.K_{s p}\right)$ vs. $1 / T(K)$ for several 1-2 and 2-2 valence metal sulfates in $\mathrm{H}_{2} \mathrm{O}$ and $\mathrm{D}_{2} \mathrm{O}$ solutions, $200-350^{\circ} \mathrm{C}$.

Hydrolytic Behavior of Sulfate Salts

Solubility relationships of several sulfate salts in water and in sulfuric acid solutions have been studied at this laboratory up to $350^{\circ} \mathrm{C}$. These have included the studies on calcium sulfate discussed in the preceding sections, magnesium sulfate (44), nickel 
sulfate $(45)$, silver sulfate $(17,46)$, lithium sulfate $(47)$, copper sulfate $(14,48,49)$, and uranyl sulfate $(14,15,49,50)$. Previously, many extensive studies of the solubility of sulfate salts in water alone were performed by A. Benrath, et al., (51) using the visual synthetic method, whereby he described a sudden, rapid decrease in solubility of salts such as magnesium sulfate and nickel sulfate occurring at about $190^{\circ} \mathrm{C}$. From the later studies of $\mathrm{MgSO}_{4}$ and $\mathrm{NiSO}_{4}$ in $\mathrm{H}_{2} \mathrm{SO}_{4}$ solutions, this drop in solubility was attributed to hydrolytic precipitation of oxysulfates and the hydroxides of magnesium and nickel at $180-200^{\circ} \mathrm{C}$. Small, excess amounts of $\mathrm{H}_{2} \mathrm{SO}_{4}$ were found to stabilize these two salts, thus producing a saturating solid phase of $\mathrm{MgSO}_{4} \cdot \mathrm{H}_{2} \mathrm{O}$ or $\mathrm{NiSO}_{4} \cdot \mathrm{H}_{2} \mathrm{O}$. Calcium sulfate and lithium sulfate as saturating solids were found to be hydrolytically stable to the high temperatures with no added solution acid.

The salts $\mathrm{UO}_{2} \mathrm{SO}_{4}$ and $\mathrm{CuSO}_{4}$, like $\mathrm{MgSO}_{4}$ or $\mathrm{NiSO}_{4}$, hydrolyzed to form an oxysulfate solid phase (from CuSO 4 solution) and an oxide $\mathrm{UO}_{3} \cdot \mathrm{H}_{2} \mathrm{O}$ (from $\mathrm{UO}_{2} \mathrm{SO}_{4}$ ) at temperatures of $200-300^{\circ} \mathrm{C}$ and at low concentrations of salt. However, at higher solution concentrations of $\mathrm{CuSO}_{4}$ (with some added $\mathrm{H}_{2} \mathrm{SO}_{4}$ ) and $\mathrm{UO}_{2} \mathrm{SO}_{4}$, a second liquid phase (not a solid) formed.

This second liquid phase was found to contain a dissolved stoichiometric excess of $\mathrm{Cu}(\mathrm{OH})_{2}$ or of $\mathrm{UO}_{2}(\mathrm{OH})_{2}$ and therefore is analogous to the precipitation of an oxysulfate or oxide from stoichiometric $\mathrm{NiSO}_{4}$ and $\mathrm{MgSO}_{4}$ solutions. The salt, $\mathrm{UO}_{2} \mathrm{~F}_{2}$, in producing liquidliquid immiscibility in the range of temperature, $300-374^{\circ} \mathrm{C}(52)$, also precipitates a $\mathrm{UO}_{3} \cdot \mathrm{UO}_{2} \mathrm{~F}_{2}$ salt or $\mathrm{UO}_{3}$ hydrate from low concentrations of salt, thus indicating hydrolytic precipitation. Other stoichiometric uranyl salts, $\mathrm{UO}_{2}\left(\mathrm{NO}_{3}\right)_{2}$ (53) and $\mathrm{UO}_{2} \mathrm{Cr}_{2} \mathrm{O}_{7}$ (54), hydrolytically precipitate a solid phase at high temperatures, but with no observed second liquid phase.

In general, it would appear that sulfate salts exhibit retrograde "solubility" behavior with increasing temperature at temperatures between 100 to $374^{\circ} \mathrm{C}$. This behavior is exhibited in different ways, either by precipitation of the stoichiometric salt or hydrate (from $\mathrm{CaSO}_{4}$ or $\mathrm{Li}_{2} \mathrm{SO}_{4}$ solutions) or of oxysulfates, oxides or hydroxides (from $\mathrm{NiSO}_{4}$ or $\mathrm{MgSO}_{4}$ solutions), or by the formation of a concentrated second liquid phase containing a stoichiometric excess of oxide.

Liquid-Liquid Immiscibility

There are several aqueous inorganic systems that separate into two liquid phases at high temperatures. Uranyl sulfate (55), uranyl fluoride (52), and copper sulfate solutions together with concentrations of sulfuric acid $(56,57)$ at an early time were found to form a dilute and a very concentrated liquid phase in equilibrium with each other at temperatures above about $290^{\circ} \mathrm{C}$. The two phases contained non-stoichiometric amounts of uranyl or cupric ions with the corresponding anion and therefore the systems needed to be described as three component systems $(15,48)$. Interestingly, as the temperature was raised, the concentrated liquid became even more concentrated and the dilute phase converted into a supercritical fluid at its critical temperature, providing moderately high concentrations of uranium or copper in the supercritical fluid.

In some recent studies, two liquid phase formation has been discovered in aqueous sodium and potassium phosphate solutions at temperatures above $275^{\circ} \mathrm{C}(58-60)$. Figure 10 shows the phase behavior observed for sodium phosphate mixtures of mole ratios sodium/phosphate varying from 1 to $3(60)$. From this figure we observe a minimum consolute solution temperature of about $291^{\circ} \mathrm{C}$ for $\mathrm{Na}_{2} \mathrm{HPO}_{4}-\mathrm{H}_{2} \mathrm{O}$ solutions, with the observed temperature rising as additional phosphoric acid is added to raise the mole ratio, $\mathrm{Na} / \mathrm{PO}_{4}$. In this system, and also for the analogous potassium system, large amounts of alkali phosphates are soluble in the supercritical fluids. Possible applications are discussed later.

\section{Liquid-Vapor Critical Temperatures}

There are few available measurements of aqueous-electrolyte liquid-vapor critical temperatures, probably because for completeness generally many pressure-volume-temperaturecomposition measurements must be made in the vicinity of 374 to $500^{\circ} \mathrm{C}$ on highly corrosive fluids (at these temperatures). Sourirajan and Kennedy have, however, made extensive measurements on the system sodium chloride-water and have published a complete phase behavior description of this system, showing a concentrated liquid phase in equilibrium with the supercritical fluid and also giving critical temperatures and pressures (61). In an 


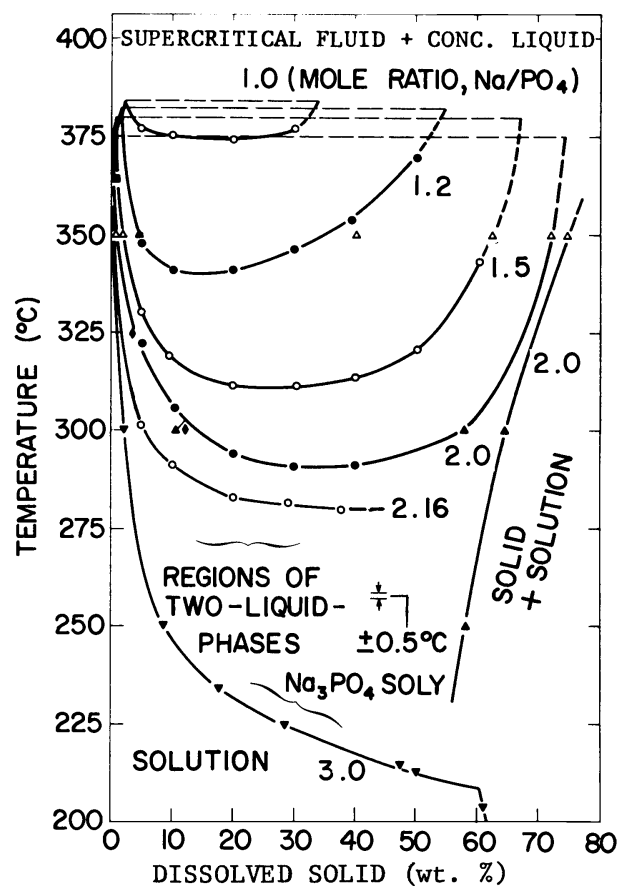

Fig. 10. Two-liquid-phase and solution-solid boundaries for aqueous solution mixtures of sodium phosphate salts of mole ratios, $\mathrm{Na} / \mathrm{PO}_{4}$, from 1.00 to 3.00 at 200 to $400^{\circ} \mathrm{C}$.

exploratory study of many separate, dissolved salts and acids, their liquid-vapor critical temperatures have been obtained by Marshall and Jones (7). Figure 11 shows an example of some of the results obtained. We observe that the critical temperature of $374^{\circ} \mathrm{C}$ for pure water is raised by as much as $100^{\circ} \mathrm{C}$ by particular dissolved salts. Above the critical temperature, the salt remains dissolved and therefore, as for the sulfate salts mentioned above, moderately high salt concentrations are stable in the supercritical fluids.

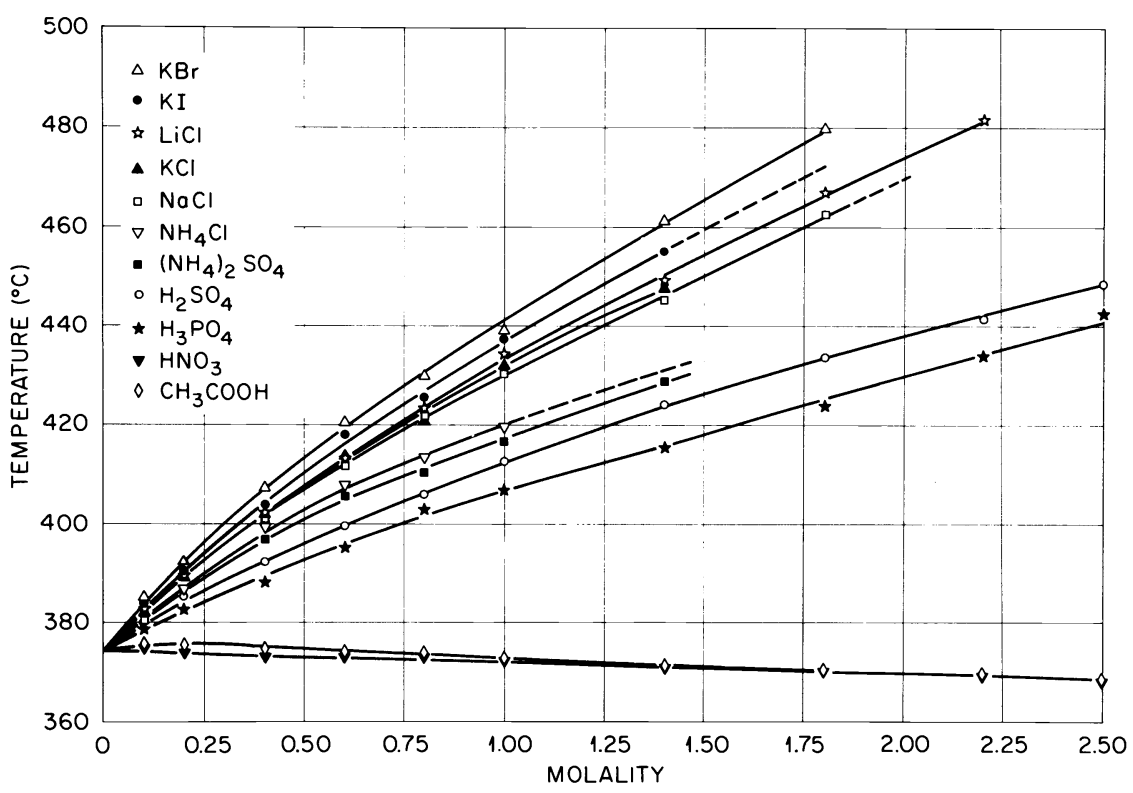

Fig. 11. Liquid-vapor critical temperatures $\left(t_{c}\right)$ of some aqueous electrolyte solutions vs molality. 
Some Effects of Pressure on Solubility

The effect of hydrostatic pressure on the temperature of formation of a second liquid phase in the system $\mathrm{UO}_{2} \mathrm{SO}_{4}-\mathrm{H}_{2} \mathrm{O}$ has been determined at this laboratory by the use of visual techniques described in the experimental section $(10,62)$. Increased pressure was found always to raise the temperature of liquid-liquid immiscibility. Figure 12 shows an example of this effect of pressure on several different concentrations of $\mathrm{UO}_{2} \mathrm{SO}_{4}$ where all curves have been normalized to the same temperature of immiscibility at saturation vapor pressure (10). It is interesting to observe that this normalization places all temperatures of immiscibility on the same line and thus provides some simplicity of description.

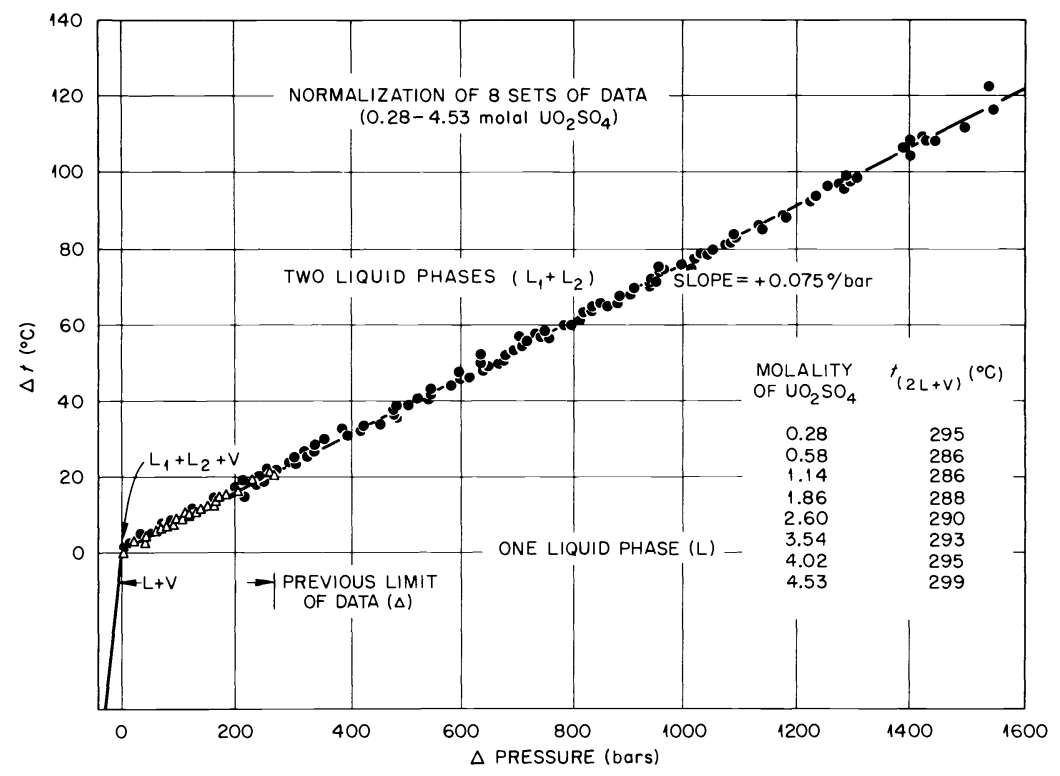

Fig. 12. Effect of hydrostatic pressure on liquid-liquid immiscibility of $\mathrm{UO}_{2} \mathrm{SO}_{4}-\mathrm{H}_{2} \mathrm{O}$ solutions. At $\Delta \mathrm{t}=0$ and $\Delta \mathrm{p}=0$, the values of $t$ and $p$ vary between $290-300^{\circ} \mathrm{C}$ and $70-90$ bars, respectively.

Blount and Dickson have determined the effect of pressure up to 1000 bars on the solubility of $\mathrm{CaSO}_{4}$ in water and in aqueous sodium chloride solutions at temperatures of 100 to $400^{\circ} \mathrm{C}(63)$. By the use of extended Debye-Hückel theory, these values of solubility may be extrapolated to zero ionic strength and the solubility product constants obtained (64). The standard volume change, $\Delta V$, may be obtained from the relationship of equation 7 . In another approach where the solvent is considered to be directly involved in the reaction process as a reactant of variable concentration, the value of $\Delta V$ may be obtained at any pressure $P$ from the relationship (42),

$$
\Delta V=-n R T \beta
$$

where $\beta$ is the coefficient of compressibility of the solvent and $n$ is believed to represent the net change in moles of solvent species (water) in the solubilization process. For the solubility of an anhydrous substance, $n$ would represent the average extent of solvation of the solute species originating from the saturating solid $(65,66)$. Plots of $\log K_{S p}$ vs $\log \mathrm{C}_{\mathrm{H}_{2} \mathrm{O}}$ at zero ionic strength yield straight lines where the slope corresponds to the values of $n(64)$. 
SOME APPLIED ASPECTS

Water Desalination

In water desalination by distillation it is imperative that formation of scales on heat exchanger surfaces be prevented. Scales may form by deposition of solids from the concentrated brines that are produced upon distilling the water. More importantly, scales may deposit at high temperature from the natural (unconcentrated) water because of the decreasing solubility with temperature both of $\mathrm{CaSO}_{4}$ and its hydrates and of other substances such as $\mathrm{CaCO}_{3}, \mathrm{MgCO}_{3}, \mathrm{Ca}(\mathrm{OH})_{2}$, and $\mathrm{Mg}(\mathrm{OH})_{2}$. Scale formation by the latter substances can be prevented by the addition of small amounts of acid to remove carbonate and neutralize excess hydroxide. The solubility of $\mathrm{CaSO}_{4}$, however, is little affected by small additions of acid. Therefore, in order to prevent scale formation by this salt, it either must be removed or the temperature-solubility limits for the particular, natural salt solution (sea, estuary, or brackish water) and its concentrates must be known in order to avoid scale formation. From the study of the solubility of $\mathrm{CaSO}_{4}$ and its hydrates in sodium chloride and seasalt solutions (27), and with knowledge of the association behavior of $\mathrm{MgSO}_{4}$ obtained also from these studies (28), the temperature-solubility limits of $\mathrm{CaSO}_{4}$ and its hydrates in natural waters are easily calculated. A published computer program for this purpose together with references to similar studies and approaches (27) has been used in the design and operation of desalination plants for predicting these limits of solubility.

\section{Power Plant Steam Generators}

Critical problems in steam generators involve corrosion and scale formation on the steam production side of the generator for both fossil fuel and nuclear steam generators. Although the water used in these steam cycles has been highly purified to the "parts per million" and even "parts per billion" range of impurities, it is essentially impossible to remove all impurities. In a steam generator operation, there is a difference in temperature within the tube walls, and consequently any crevice that might initially be present or be produced may collect steam generator water that then may concentrate any soluble impurities by evaporation or boiling. Predominant dissolved impurities are sulfate, chloride, hydroxide, sodium, and hydrogen ions, and silica, resulting in potential precipitations of $\mathrm{Na}_{2} \mathrm{SO}_{4}$ and silica or silicates.

Iron and nickel oxides can also form from metal surfaces within steam generators, and these substances can combine with silica and other dissolved impurities to form precipitates or scales. The experimental measurements and interpretations cited above, together with solubility studies of iron oxides in water of Sweeton and Baes (67) at this laboratory and of Tremaine and Le Blanc $(68,69)$ on both iron and nickel oxides at temperatures up to $400^{\circ} \mathrm{C}$ have allowed the prediction of the precipitation limits of salts, in particular, $\mathrm{Na}_{2} \mathrm{SO}_{4}$, and the phase behavior of oxides, for example, iron oxides, amorphous silica, and quartz. The experimental values of iron and nickel oxide solubilities were obtained by forcing very pure water through a column bed of oxide and analyzing for the solubilized metal species (67-69).

\section{Geothermal Power}

In geothermal power technology, knowledge of the solubility relations of dissolved substances in the subsurface thermal waters, and their expected solubility behavior upon power plant throughput, is required for satisfactory plant design and operation. For example, there are changes in pressure, temperature, and perhaps dissolved gas content (where the gases may include reactive $\mathrm{CO}_{2}, \mathrm{H}_{2} \mathrm{~S}$, or $\mathrm{SO}_{2}$ ) of the thermal waters on use, and these changes may allow the formation of scales or affect the extent of corrosiveness by the waters. The ability to predict the solubility of particular substances (for example, hydroxides, carbonates, sulfates, and sulfites of several cationic species) is needed for plant operation in order to adapt to changing composition, pressure, and temperature of the thermal waters, and to predict the feasibility of new operations. Ellis and Mahon (New Zealand) made solubility measurements on a variety of salts to temperatures of $200-300^{\circ} \mathrm{C}$ on the basis both of fundamental and applied considerations $(70,71)$. They used their measurements directly and predictively to aid in the successful operation of the early geothermal power station near Taupo, North Island, New Zealand. Their published studies have been of much interest to geothermal operations elsewhere and for their fundamental value. 
Most geothermal power steam generators operate from geothermal waters that do not contain excessively large quantities of dissolved salts, and therefore for a particular solute, dissolved silica, the many published solubilities in pure water at high temperatues have been used for estimating and designing steam generators to prevent scale formation by silica. [In contrast to the sulfate salts discussed above, silica solids, either as amorphous silica, cristobalite, or quartz, are less soluble at low rather than at high temperatures. In geothermal plants the geothermal waters contain dissolved silica at high temperatures that upon subsequent cooling in the distillation process may thus precipitate.] The geothermal aqueous fields in the Imperial Valley of California, USA, however, consist of very concentrated brines that contains dissolved silica in equilibrium with quartz as the solid. Upon cooling in geothermal steam generators, it is possible that the solubility of amorphous silica is exceeded, and thus this solid may precipitate as a scale on heat exchanger surfaces. The extensive study of amorphous silica solubilities in high temperature aqueous concentrates of electrolytes present in natural waters has allowed the prediction of temperature-composition limits of solubility of amorphous silica (37). This information was very useful in the design of the first commercial geothermal power plant in the Imperial Valley of California, USA [Union 0il Company of California] and in the design of subsequent plants in this valley.

Geochemistry and Related Fundamental Studies

The field of geochemistry as it relates to aqueous solutions is concerned with the general hydrothermal behavior of electrolytes. Consequently, knowledge of the solubility of various substances is of great importance in developing theories and mechanisms of hydrothermal processes, including ore formation, diagenesis, alteration, and metamorphism. By combining experiment with theory, one hopes to make predictions of solubility behavior outside of the range of the experiments. Many past and present investigators have made studies of the hydrothermal behavior of electrolytes, where their interests have been directly or indirectly concerned with geochemistry. Tabulations of many of these earlier investigators have appeared elsewhere $(1,2)$.

Khodakovskii and associates have made extensive phase equilibrium and thermodynamic studies on high temperature aqueous electrolytes of geological interest. Some of this work is reviewed elsewhere $(72,73)$. There have been many experimental aqueous phase studies of hydrothermal geological interest published by Barnes and colleagues. Barnes has edited a book on this subject, including chapters by different authors on several aspects of high temperature equilibria (74). Valyashko, et al., have published numerous papers on the high temperature phase behavior of many types of aqueous systems. They have studied multicomponent, highly concentrated, aqueous systems at temperatures from 200 to $500^{\circ} \mathrm{C}$. Some recent reviews by Valyashko are given el sewhere $(75,76)$.

There are several recent theoretical and semi-theoretical approaches applied to describing high temperature aqueous systems in general and to predicting phase stability behavior of minerals. Helgeson, et al., have devoted considerable effort toward this direction $(77,78)$ and Pitzer, et al., have published many papers on the thermodynamic behavior of electrolytes, with particular emphasis on $\mathrm{NaCl}_{-} \mathrm{H}_{2} \mathrm{O}$ at high temperatures (79-81), the results of which can be applied to predicting phase behavior of salts in these aqueous media.

\section{Hydrothermal Synthesis}

Knowledge of the synthesis of minerals and the growing of particular mineral crystal structures from aqueous subcritical and supercritical fluids at high temperatures $\left(300-500^{\circ} \mathrm{C}\right)$ is of practical importance to several industries. Based upon the earlier experimental studies of Laudise, et al., (82), large crystals of quartz and of many other minerals that are used for constant frequency oscillators, and for several other purposes in industry, are produced economically by hydrothermal synthesis. High quality gems are also produced by this method.

\section{Chemical Oceanography}

The solubilities of substances such as $\mathrm{CaSO}_{4}$, carbonates, silica, or hydroxides in ocean waters as a function of temperature, dissolved gases, and pressure are of importance in evaluating both physical and biological oceanographic processes. Thus, questions have arisen as to which solid, $\mathrm{CaSO}_{4}$ or $\mathrm{CaSO}_{4} \cdot 2 \mathrm{H}_{2} \mathrm{O}$, is the most stable one in equilibrium with 
the solution phase at low temperatures $\left(25-50^{\circ} \mathrm{C}\right)(16,83)$. The definite answer to this question allows prediction of paleoenvironmental temperatures in geological time, for example, during the formation time of sediments in the Dead Sea area and elsewhere (83a). The solubility behavior of carbonates is of interest in evaluating the biological formation of corals and seashells.

Very recently, the discovery of deep ocean hot springs (84), with vent temperatures up to $350^{\circ} \mathrm{C}$, has excited very much interest by chemical oceanographers in the phase behavior of the thermally precipitating minerals in the vicinity of the springs. Of particular interest has been the solubility and hydrolytic behavior of metal sulfides for which considerable experimental measurements are needed. The silica solubility studies in concentrated salt solutions, discussed above, have been useful for establishing solubility limits of silica from which core temperatures of the suboceanic hot springs may be evaluated.

Aqueous Supercritical Fluids for Phase Separations

Studies of the aqueous supercritical fluids, discussed above, have shown that moderately large amounts of salts are soluble in these fluids. In some cases, a concentrated liquid phase can coexist with the supercritical fluid. Applications of supercritical fluids to the separation and purification of substances have expanded greatly in the past several years. These processes have generally involved the use of organic solvents or of substances like carbon dioxide that do not have excessively high critical pressures or temperatures and are generally non-corrosive to metal containers. In contrast, water has a crtical temperature of $374^{\circ} \mathrm{C}$ and critical pressure of 221 bars, and with dissolved inorganic substances is generally strongly corrosive to conventional containing materials at the high temperatures. Nevertheless, if there is sufficient motivation for a process, these problems of extreme conditions can probably be solved. Presently, there would appear to be much development elsewhere on the separation of components of coal with high temperature water. Some of the organic components melt and partially or wholly dissolve in high temperature subcritical and supercritical water, thereby allowing possible separations. With suitable incentives, it is likely that inorganic substances, such as the metallic species discussed above, could be separated by processes occurring in the supercritical fluid regions.

\section{Early Applications to Aqueous Homogeneous Nuclear Power Reactors}

At earlier times (1947-60), much work at this laboratory was devoted to the development of nuclear power test reactors for operation at $250-300^{\circ} \mathrm{C}$ using an aqueous, dissolved solution of uranyl sulfate as the fuel $(85,86)$. This project motivated our development of experimental techniques for studying high temperature aqueous systems, especially in the exploration of uranium containing aqueous systems. The phase-equilibrium studies were applied in the operation of two aqueous homogeneous nuclear power reactors at 0ak Ridge $(85,86)$. All later studies on high temperature aqueous systems at this laboratory evolved from this early work.

\section{CONCLUSIONS}

In this paper, a review of some solubilities in aqueous solutions at high temperatures and of some liquid-vapor critical temperatures that have been studied generally at this laboratory, together with experimental techniques that were used, has been presented. The methods of interpretation have allowed some simplicity in the description of solubility equilibria over wide ranges of temperature, pressure, and dissolved electrolyte concentrations. Several applied aspects are presented briefly. It is hoped that some of the approaches used can be adapted to other studies of high temperature phase equilibria for practical benefit.

\section{ACKNOWLEDGEMENTS}

I wish to thank the organizers of the First International Solubility Symposium of IUPAC for inviting me to deliver the plenary lecture upon which this paper is based. I also would like to recognize the numerous contributions to this work by my many colleagues and 
co-authors over many years of research at ORNL. A majority of the reported work (1947-1984) has been sponsored by the U.S. Government through the basic research programs of the Department of Energy and its predecessor organizations. This review paper is sponsored by the Division of Chemical Sciences, Office of Basic Energy Sciences, U.S. Department of Energy, under contract DE-AC05-840R21400 with the Martin Marietta Energy Systems, Inc.

\section{REFERENCES}

1. W. L. Marshal1, Rev. Pure Appl. Chem. 18, 167 (1968).

2. W. L. Marshal1, Rec. Chem. Prog. 30, 61 (1969).

3. W. L. Marshal1, "High Temperature High Pressure Electrochemistry in Aqueous Solution", Nat. Assn. Corrosion Engineers Publ. NACE-4, Houston, Texas, USA, pp. 117-130 (1976).

4. W. L. Marshall, Chem. Geol. 10, 59 (1972).

5. W. L. Marshal1, Chemistry 48, 6 (1975).

6. W. L. Marshall and E. V. Jones, J. Inorg. Nucl. Chem. 25, 1021 (1963);

W. L. Marshall, E. V. Jones, G. M. Hebert and F. J. Smith, ibid. 24, 995 (1962); C. J. Barton, G. M. Hebert and W. L. Marshall, ibid. 21, 141 (1961), plus many previous papers.

7. W. L. Marshall and E. V. Jones, J. Inorg. Nucl. Chem. 36, 2313 (1974).

8. W. L. Marshall, H. W. Wright and C. H. Secoy, J. Chem. Educ. 31, 34 (1954).

9. C. J. Barton, G. M. Hebert and W. L. Marshall, J. Inorg. Nucl. Chem. 21, 141 (1961).

10. W. L. Marshall and J. S. Gill, J. Inorg. Nucl. Chem. 36, 2303 (1974).

11. J. S. Gill and W. L. Marshall, Rev. Sci. Instr. $34,4 \overline{42}$ (1963).

12. W. L. Marshall and E. V. Jones, J. Phys. Chem. 70,4028 (1966).

13. J. S. Gill and W. L. Marshall, Rev. Sci. Instr. 32, 1060 (1961).

14. W. L. Marshall and J. S. Gill, J. Inorg. Nucl. Chem. 22, 115 (1961).

15. E. V. Jones and W. L. Marshall, J. Inorg. Nucl. Chem. 23, 287 (1961).

16. W. L. Marshall and R. Slusher, J. Phys. Chem. 70, 4015 (1966).

17. M. H. Lietzke and R. W. Stoughton (a): J. Inorg. Nucl. Chem. 28, 1877 (1966); J. Phys. Chem. 64, 133816 (1960); ibid. 63, 1183, 1186, 1188, $1190,198 \overline{4,(1959) ; ~ J . ~ A m . ~ C h e m . ~ S o c . ~} 78,30 \overline{23}(19 \overline{56})$; J. Phys. Chem. 67, 652 (1963); (b) M. H. Lietzke, R. W. Stoughton and T. F. Young, ibid. 65, 2247 (1961).

18. W. L. Marshall and R. Slusher, J. Chem. Thermodynamics 5, 189 (1973).

19. W. L. Marshal 1, R. Slusher and E. V. Jones, J. Chem Eng. Data 9, 187 (1964).

20. R. Kalyanaraman, L. B. Yeatts and W. L. Marshall, J. Chem. Thermodynamics $\underline{5}$, 891 (1973).

21. L. B. Yeatts and W. L. Marshall, J. Phys. Chem. 71, 2641 (1967).

22. M. H. Lietzke and W. L. Marshall, "Sodium Sulfate Solubilities in High-Temperature $\left(250-374^{\circ} \mathrm{C}\right)$ Salt and Acid Solutions", Electric Power Research Institute Report EPRI NP-3047, Menlo Park, California (July 1983).

23. F. H. Sweeton, R. E. Mesmer and C. F. Baes, Jr., J. Solution Chem. 3, 191 (1974).

24. R. H. Busey and R. E. Mesmer, J. Chem. Eng. Data 23, 175 (1978).

25. M. H. Lietzke and R. W. Stoughton, J. Inorg. Nucl. Chem. 28, 1063 (1966).

26. W. L. Marshall and R. Slusher, J. Inorg. Nucl. Chem. 37, 2171 (1975).

27. W. L. Marshall and R. Slusher, J. Chem. Eng. Data 13, 83 (1968).

28. W. L. Marshal1, J. Phys. Chem. 71, 3584 (1967).

29. W. L. Marshall and R. Slusher, J. Inorg. Nucl. Chem. 37, 1191 (1975).

30. W. L. Marshall and R. Slusher, J. Inorg. Nucl. Chem. 37,2165 (1975).

31. L. B. Yeatts and W. L. Marshall, J. Phys. Chem. 73, 81 (1969).

32. R. Kalyanaraman, L. B. Yeatts and W. L. Marshal1, J. Chem. Thermodynamics 5 , 899 (1973).

33. W. L. Marshal1, Geochim. Cosmochim. Acta 44, 907 (1980).

34. W. L. Marshall and J. M. Warakomski, Geochim. Cosmochim. Acta 44, 915 (1980).

35. W. L. Marshal1, Geochim. Cosmochim. Acta 44, 925 (1980).

36. C.-T. A. Chen and W. L. Marshal1, Geochim. Cosmochim. Acta 46, 279 (1982). 
37. W. L. Marshall and C.-T. A. Chen, Geochim. Cosmochim. Acta 46, 289 (1982). 38. W. L. Marshall and C.-T. A. Chen, Geochim. Cosmochim. Acta $\frac{46}{4}, 367$ (1982).

39. R. 0. Fournier and W. L. Marshall, Geochim. Cosmochim. Acta 47, 587 (1983).

40. R. 0. Fournier and R. W. Potter, Geochim. Cosmochim. Acta 46, 1969 (1982).

41. R. 0. Fournier, Geochim. Cosmochim. Acta 47, 579 (1983).

42. W. L. Marshal1, J. Phys. Chem. 74, 346 (1970).

43. W. L. Marshal1, J. Inorg. Nucl. Chem. 37, 2155 (1975).

44. W. L. Marshall and R. Slusher, J. Chem. Eng. Data 10, 353 (1965).

45. W. L. Marshall, J. S. Gill, and R. Slusher, J. Inorg. Nucl. Chem. 24, 889 (1962).

46. W. L. Marshall and R. Slusher, J. Inorg. Nucl. Chem. 38, 279 (1976).

47. W. L. Marshall, R. Slusher, and F. J. Smith, J. Inorg. Nucl. Chem. 25, 559 (1963).

48. E. V. Jones and W. L. Marshall, J. Inorg. Nucl. Chem. 23, 295 (1961).

49. W. L. Marshall and E. V. Jones, J. Inorg. Nucl. Chem. $\frac{25}{72}, 1021$ (1963).

50. C. H. Secoy, J. Am. Chem. Soc. 70,3450 (1948); ibid. $\overline{72}, 3343$ (1950).

51. A. Benrath, Z. Anorg. Chem. 252, 86 (1943); Z. Anorg. Allgem. Chem. 249, 245 (1942); ibid. 247, $147(1941) ;$ A. Benrath and A. Braun, ibid. 244,348 (1940); A. Benrath and K. Lechner, ibid. 244, 359 (1940) ; plus many earlier publications, (1920-1940).

52. W. L. Marshall, J. S. Gill and C. H. Secoy, J. Am. Chem. Soc. 76, 4279 (1954).

53. W. L. Marshall, J. S. Gill and C. H. Secoy, J. Am. Chem. Soc. 73, 1867 (1951); Oak Ridge National Laboratory Report ORNL-1053, P. 22 (1951).

54. F. J. Loprest, W. L. Marshall and C. H. Secoy, J. Amer. Chem. Soc. 77, 4705 (1955).

55. C. H. Secoy, J. Am. Chem. Soc. 72,3343 (1950).

56. F. E. Clark, J. S. Gill, R. Slusher and C. H. Secoy, J. Chem. Eng. Data 4 , 12 (1959).

57. W. L. Marshall, E. V. Jones, G. M. Hebert and F. J. Smith, J. Inorg. Nucl. Chem. 24, 995 (1962).

58. D. Broadbent, A. D. Brewer, and B. Hearn, Trans. Farad. Soc. 67,2419 (1971).

59. W. L. Marshall, C. E. Hall and R. E. Mesmer, J. Inorg. Nucl. Chem. 43, 449 (1981).

60. W. L. Marshal1, J. Chem. Eng. Data 27, 175 (1982).

61. S. Sourirajan and G. C. Kennedy, Amer. J. Sci. 260, 115 (1962).

62. W. L. Marshall and J. S. Gill, J. Inorg. Nucl. Chem. 25, 1033 (1963).

63. C. W. Blount and F. W. Dickson, Geochim. Cosmochim. Acta 33, 227 (1969).

64. W. L. Marshal1, J. Phys. Chem. 76,720 (1972).

65. W. L. Marshall and A. S. Quist, Proc. Nat. Acad. Sci. 58, 901 (1967).

66. A. S. Quist and W. L. Marshall, J. Phys. Chem. 72, 1536 (1968).

67. F. H. Sweeton and C. F Baes, Jr., J. Chem. Thermodynamics 1970, 479 (1970).

68. P. R. Tremaine and J. C. LeBlanc, J. Solution Chem. $9,415(1980)$.

69. P. R. Tremaine and J. C. LeBlanc, J. Chem. Thermodynamics 12, 521 (1980).

70. A. J. Ellis, Bull. Volcanology 29, 575 (1966); Amer. J. Sci. 261, 259 (1963); ibid, 28, 1323 (1964).

71. W. A. J. Mahon, New Zeal and J. Sci. 10, 206 (1967); Geochim. Cosmochim. Acta 31, 519 (1967); ibid. 28, 1323 (1964).

72. I. L. Khodakovskii, Proc. Int. Symp. Hydrotherm. React. 1st, S. Somiya, ed., Gakujutu Bunken Fukyu-kai: Tokyo, Japan (1983).

73 I. L. Khodakovskii, Fiz-Khim. Probl. Gidroterm. Magmat. Protsessov., 1975, 124; A. I. Tugarinov, ed., "Nauka", Moscow, USSR (1975).

74. H. L. Barnes and S. Malinin, "The Solubility and Occurrence of Non-Ore Minerals", Chapter 9, In Geochemistry of Hydrothermal Ore Deposits, 2nd ed., (H. L. Barnes, editor), Wiley Interscience Publ., New York, 1975.

75. V. M. Valyashko, "Phase Equilibria and Properties of Aqueous Solutions at High Temperatures and Pressures", Proceedings, Tenth International Conference on the Properties of Steam, Moscow, USSR, Sept. 2-7, 1984; to be published. 
76. V. M. Valyashko and K. G. Krauchuk, "Characteristics of the Structure of Phase Diagrams of Binary and Ternary Systems Composed of Components of Varying Solubility", Eksp. Issled. Endo. Rudoobraz., V. A. Zharikov, editor, Izd. Nauka, Publ., Moscow, USSR (1983).

77. H. C. Helgeson and D. H. Kirkham, Am. J. Sci. 274, 1089, 1199 (1974); ibid. 276, 97 (1976).

78. H. C. Helgeson, D. H. Kirkham and G. C. Flowers, Am. J. Sci. 281, 1249 (1981).

79. K. S. Pitzer, J. Phys. Chem. 77, 263 (1973).

80. K. S. Pitzer and G. Mayorga, J. Phys. Chem. 77,2300 (1973).

81. K. S. Pitzer and J. J. Kim, J. Amer. Chem. SoC. 96, 5701 (1974).

82. R. A. Laudise, "The Growth of Single Crystals", Prentice-Hall Publ., Englewood Cliffs, NJ (1970); Endeavour 28, (105), 114 (1969); R. A. Laudise and A. A. Ballman, Kirk-0thmer Encycl. Chem. Technol. 2nd ed., 18, 105 (1969) ; R. A. Laudise, J. Phys. Chem. Solids, Suppl . No. 1, 3 (1967).

83. (a) L. A. Hardie, Am. Mineralogist 52, 171 (1967); (b) E-An Zen. J.

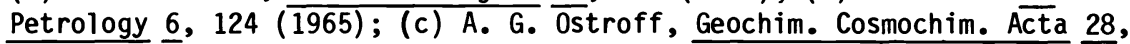
$1363(1964)$.

84. J. B. Corliss, et al., Science 203, 1073 (1979).

85. J. A. Lane, H. G. MacPherson and F. Maslan, editors, "Fluid Fuel Reactors", Addison-Wesley Publ., Reading, Mass., USA (1958).

86. J. K. Dawson and R. G. Sowden, "Chemical Aspects of Nuclear Reactors", vol. 2, "Water-Cooled Reactors", Butterworths Publ., London (1963). 